\title{
VERBOS DE MOVIMIENTO, CAMBIOS DE ESTADO Y CATEGORIZACIÓN DE AFECCIONES*
}

\author{
VERBS OF MOTION, CHANGE OF STATE AND THE \\ CATEGORIZATION OF PHYSICAL AND MENTAL DISORDERS
}

\author{
BERTA CROUS \\ Lingüística General, Universitat de Girona \\ berta.crous@udg.edu \\ LLUÏSA GRÀCIA \\ Lingüística General, Universitat de Girona. \\ lluisa.gracia@udg.edu
}

\section{RESUMEN}

En este trabajo se muestra de qué modo influye la categorización que los hablantes del catalán hacen de las afecciones (enfermedades, signos, síntomas, lesiones, etc.) en la elección del verbo y en la estructura sintáctica de las frases en las que se expresa la relación entre una afección y la entidad animada afectada por ella. Se toman en consideración los verbos agafar 'coger, agarrar' (transitivo e inacusativo), venir 'venir' y sortir 'salir', que se pueden utilizar para expresar la aparición de una afección, proceso que es entendido como el movimiento de esta afección hacia una persona o desde su interior. Se ha detectado que hay al menos tres propiedades atribuidas a las afecciones que pueden condicionar el uso de estos verbos: la delimitación temporal y el alcance corporal de la afección, y el hecho de que tengan un origen interno o externo al organismo. También se compara el uso de estos tres verbos de cambio de estado con el del verbo estativo tenir 'tener', que se puede utilizar para expresar el estado posterior a la aparición de la afección.

Palabras clave: Categorización de afecciones físicas y mentales, verbos de movimiento, verbos de cambio de estado, estructura sintáctica.

\footnotetext{
* Este trabajo se ha beneficiado de una ayuda del Ministerio de Ciencia e Innovación (FFI200907635 (FILO)) y de otra del Ministerio de Economía y Competitividad (FFI2012-31415). Agradecemos a: A. Baltasar, C. Ferrerós, R. Gómez-Ten, G. Rigau, R. Viñas de Puig y, de un modo especial, a F. Roca, sus comentarios sobre el trabajo. Los errores que puedan haber quedado son exclusivamente responsabilidad nuestra.
} 


\begin{abstract}
This paper shows how Catalan speakers' categorization of physical and mental dirsorders influences the verb selection and the syntactic structure of the sentences expressing the relation between a disorder and the animate entity it affects. The verbs taken into consideration are agafar 'to take' (transitive and inaccusative), venir 'to come' y sortir 'to go out'. These verbs can be used to express the appearance of a disorder, a process that can be viewed as the movement of the disorder towards a person or from his interior. Three properties attributed to the disorder that can determine the use of the verbs have been detected: its temporal delimitation, its corporal scope and its origin, internal or external to the organism. The use of these three verbs of change of state is also compared to the stative verb tenir 'to have', which can be used to express the state subsequent to the disorder appearance.
\end{abstract}

Keywords: Physical and mental disorder categorization, verbs of motion, verbs of change of state, syntactic structure.

Recibido: 03.07.2014. Aceptado: 25.03.2015.

\title{
1. INTRODUCCIÓN
}

l objetivo de este trabajo es aportar pruebas a favor de la hipótesis según la cual Cla categorización es uno de los factores que pueden condicionar la selección de elementos léxicos y de estructuras sintácticas en una lengua. Para ello, se analizará los usos de los verbos de movimiento venir 'venir' y sortir 'salir', ${ }^{1}$ y del verbo agafar 'coger, agarrar' del catalán cuando expresan la manifestación de afecciones, ${ }^{2}$ generalmente patológicas, y veremos qué elementos condicionan la distribución de sus usos.

La categorización es un proceso que consiste en discernir y reagrupar las distintas entidades del mundo real en categorías, es decir, en distinguir rasgos co-

\footnotetext{
${ }^{1}$ Hay otro verbo de movimiento que también se puede utilizar en catalán para expresar la adquisición o manifestación de afecciones, pero que no se analizará en este trabajo: entrar 'entrar'. Este verbo se puede utilizar básicamente en dos estructuras distintas: El noi ha entrat en crisi / en coma 'El chico ha entrado en crisis / en coma', con el nombre que designa la afección dentro de un sintagma preposicional (generalmente con en); y Al noi li ha entrat gana 'Al chico le ha entrado hambre', con este nombre como sujeto y un dativo que expresa la persona afectada. En este último caso, tanto las autoras como la mayoría de hablantes consultados prefieren los verbos agafar (no transitivo) y venir a entrar, cuyo uso consideran más marginal y perciben como una influencia del castellano.

2 Para simplificar la exposición, se usará la palabra afección para referirnos a las enfermedades, síndromes, signos, síntomas, sensaciones y lesiones citados en este artículo. No se usará, pues, esta palabra en el sentido exclusivamente médico de "5. alteración morbosa" (DRAE, s.v. afección). Se incluyen también el significado más general de "1. Impresión que hace una cosa en otra, causando en ella alteración o mudanza” y "2. Afecto, pasión del ánimo”.
} 
munes que permite incluirlas dentro de una misma clase. Este concepto ha sido ampliamente estudiado en el modelo de la Lingüística Cognitiva (cf. los trabajos ya clásicos de Lakoff y Johnson (1980), Langacker $(1987,1991)$ y (2000), Lakoff (1987) y Talmy (2000)). En este caso se tratará de ver cómo la categorización de las afecciones realizada por los hablantes de catalán, es decir las propiedades que se les asignan, puede contribuir a explicar el uso de los verbos mencionados.

Las estructuras que se analizan en este artículo, como hemos dicho, contienen los verbos agafar, venir y sortir. Como en muchas otras lenguas, además del uso más general de estos verbos, es decir el de denotar el movimiento de una entidad física por una trayectoria con un origen y un final, en catalán también se pueden utilizar para relacionar una persona con una afección: ${ }^{3}$

(1) a. La Rosa ha agafat la grip

'Rosa ha cogido la gripe'

A l'Eva li va agafar mal de panxa

'A Eva le cogió [vino] dolor de barriga'

A la Pepa li ha vingut fred

'A Pepa le ha venido [entrado] frío'

A la Marta li va sortir un gra al peu

'A Marta le salió un grano en el pie'

En primer lugar, en el apartado 2 se caracterizará los tres verbos tomados en consideración (agafar, venir y sortir) y sus argumentos, centrados en la descripción de las frases que expresan la manifestación de una afección en una persona. En este mismo apartado se describirá la distribución de usos de los tres verbos, comparándola con la del verbo tenir 'tener'. Y en segundo lugar, en el apartado 3 se describirá la distribución de usos de las frases con agafar, venir y sortir, poniendo énfasis en las propiedades atribuidas a las afecciones que condicionan el uso de uno u otro verbo.

Para realizar esta descripción las autoras se han basado en nuestra competencia como hablantes de catalán y en consultas a otros hablantes nativos, entre los que se han incluido profesionales del ámbito de la salud. También se ha consultado, en caso de dudas, los datos del Corpus Textual Informatitzat de la Llengua Catalana (CTILC) del Institut d'Estudis Catalans.

\footnotetext{
${ }^{3}$ Las traducciones al castellano de los verbos de los ejemplos catalanes son literales, por lo tanto, los valores de gramaticalidad asignados a las frases catalanas no les conciernen. Se indica entre corchetes uno de los posibles verbos castellanos que podrían usarse en cada caso. El verbo coger puede alternar con pillar en un contexto más informal (He cogido/pillado un resfriado).
} 


\section{CARACTERIZACIÓN GENERAL DE LAS ESTRUCTURAS}

\subsection{Caracterización de los verbos sortir, venir y agafar}

La definición del Diccionari de la llengua catalana (DIEC2) de los verbos sortir, venir y agafar pone de manifiesto que los tres son polisémicos: en las tres entradas hay una acepción, además de la más general, que describe las construcciones en las que se basará este trabajo (se seleccionó algunos de los ejemplos más relevantes para este estudio):

\section{(2) SORTIR}

1) intr. Alguna persona o cosa, passar de dins a fora. Hem sortit del teatre a les vuit. ('Alguna persona o cosa, pasar de dentro hacia afuera. Hemos salido del teatro a las ocho').

2) intr. Allò que estava ocult, aparèixer, manifestar-se, aparèixer a la superfície, a la llum. La sang li sortia a raig fet. Li ha sortit un gra al braç. ('Aquello que estaba oculto, aparecer, manifestarse en la superficie, a la luz. La sangre le salía a chorros. Le ha salido un grano en el brazo').

(3) VENIR

1) intr. Algú, transportar-se d'un lloc al lloc on és qui parla o aquell a qui parla, moure's amb moviment contrari al designat per anar: Vine, acosta't, que the de dir una cosa. ('Alguien, transportarse de un lugar al lugar donde está el que habla o aquel a quien se habla, moverse con movimiento contrario al designado por anar 'ir': Ven, acércate, que te tengo que decir una cosa').

2) intr. Un fenomen fisiològic o anímic, iniciar-se. Em ve son. M’ha vingut migranya. ('Un fenómeno fisiológico o anímico, iniciarse. Me viene [entra] sueño. Me ha venido migraña').

\section{(4) AGAFAR}

1) tr. Subjectar, fer-se seu (quelcom) amb la mà o un altre òrgan o un instrument adequat, per tenir-ho que no se'n pugui anar, aguantar-ho, emportar-s'ho, transportar-ho, per servir-se'n, per possessionar-se'n. Agafar la paella pel mànec. ('Sujetar, hacerse suyo (algo) con la mano u otro órgano o un instrumento adecuado, para mantenerlo al alcance, sostenerlo, llevárselo, transportarlo, para servirse de él, para tomar posesión de él: Coger la sartén por el mango').

2) intr. Sobrevenir. Li ha agafat son, mal de cap, fred. I tr Contreure. Agafar un refredat. Agafar son, gana. ('Sobrevenir. Le ha cogido [entrado] sueño, dolor de cabeza, frio. | Contraer. Coger un resfriado. Coger sueño, hambre'). 
Por lo que se refiere a los verbos sortir y venir en su uso más general, son verbos inacusativos que indican el movimiento de una entidad, el sujeto, de un lugar a otro. ${ }^{4}$ El sujeto se interpreta como un Tema afectado (por un cambio de lugar o por un cambio de estado o existencia). Estos verbos, además, tienen otro argumento, un locativo de Origen. Tanto venir como sortir son verbos de movimiento de dirección inherente, es decir, verbos que llevan incorporada la dirección en el significado (verbs of inherently directed motion (Levin, 1993)). Venir expresa un movimiento centrípeto, de fuera hacia dentro: representa un movimiento de acercamiento, el movimiento de una entidad hacia el lugar donde se halla uno de los interlocutores. El hecho de que el verbo ya exprese de manera inherente un movimiento de acercamiento facilita que aparezca con un complemento preposicional que indique el origen (venir de París (cap aqui) 'venir de París (hacia aquí)'). Sortir, en cambio, indica un movimiento centrífugo, de dentro hacia afuera. En su uso prototípico como verbo de movimiento, acepta tanto un complemento que indique el origen del movimiento (sortir de casa 'salir de casa') como uno que indique la meta (sortir al balcó 'salir al balcón'); ambos complementos también pueden coaparecer (sortir de casa cap a l'hospital 'salir de casa hacia el hospital'). ${ }^{5}$

Por lo que respecta a las diferencias entre los usos prototípicos y los no prototípicos, se puede observar que están relacionadas con una pérdida o cambio de valores sintáctico-semánticos. Considérese primero el caso de sortir: ${ }^{6}$

(5) a. En Joan ha sortit de casa (cap a l'escola) 'Juan ha salido de casa (hacia a la escuela)'

b. Li surt sang del nas (*a la camisa) 'Le sale sangre de la nariz (*a la camisa)'

c. Li ha sortit un gra (*de / *ap al nas) 'Le ha salido un grano (*de/*hacia la nariz)'

d. Li ha sortit un gra al nas 'Le ha salido un grano en la nariz'
TAL $^{7}$ Origen Meta

TAL Origen *Meta

TAA * Origen ${ }^{*}$ Meta

TAA Loc

${ }^{4}$ Aunque la gramática tradicional ha considerado estos verbos como intransitivos, en el marco de la Gramática Generativa, algunos autores han analizado como inacusativos tanto estos verbos como las estructuras no transitivas con el verbo agafar. Esta será la opción tomada en este trabajo. Para un análisis más detallado de los llamados verbos inacusativos (y ergativos), cf. los trabajos clásicos de Burzio (1986), Belletti (1988), Levin y Rappaport (1995) y, para el catalán, Gràcia (1989a) y (1989b), entre otros.

${ }^{5}$ Se considerará que los complementos Origen y Meta que se pueden realizar en estas construcciones son argumentos, aunque en algunos casos puedan no especificarse porque el significado del propio verbo ya implica inherentemente una direccionalidad.

${ }^{6}$ En este trabajo no se estudia frases con sortir como Ja ha sortit de la malaltia / del coma 'Ya ha salido de la enfermedad / del coma'. En este caso, el sintagma preposicional suele expresar una afección patológica, que es entendida como un lugar del cual se puede salir.

${ }^{7}$ Se usan las siguientes abreviaturas: TAL: Tema Afectado por cambio de locación; TAA: Tema Afectado por cambio de estado (aparición), Loc: Locativo no direccional. 
Mientras que en (5a) y en (5b) el verbo selecciona un argumento con el papel temático Tema que, en estos casos, se interpreta como afectado por un cambio de lugar (TAL), en (5c) y (5d) la afectación del tema está relacionada con un cambio de estado, concretamente por su aparición (TAA). Por otra parte, en (5a) y en (5b) también se puede realizar el argumento Origen (de casa, del nas) y, en el primer caso, pero no en el segundo, el de Meta (cap a l'escola vs. *ap a la camisa). En el ejemplo, (5c), no se pueden realizar ni el Origen ni la Meta. Cuando el verbo sortir expresa la aparición de una afección, solo se explicita el origen si hay un movimiento evidente desde el interior del cuerpo hacia afuera, como en sortir sang del nas 'salir sangre de la nariz'. En otras palabras, en sortir sang del nas hay un Tema (la sangre) que se desplaza y en sortir un gra, el Tema aparece. ${ }^{8}$ Así, en el primer caso sortir se podría sustituir por rajar 'manar' (aunque el uso de este verbo está sujeto a ciertas restricciones), en cambio, en el segundo caso equivaldría a aparèixer 'aparecer.' '. Cuando el argumento Tema pasa a ser TAA (en lugar de TAL) el complemento locativo no puede expresar ninguna noción propia de un desplazamiento (ni Origen ni Meta) y pasa a expresar una locación no especificada que se ha indicado como Loc. en $(5 \mathrm{~d}) .{ }^{10}$ En otras palabras, sortir tiene, en la versión prototípica, un complemento locativo complejo que implica desplazamiento (Origen y Meta). En la versión de (5c, d) este complemento locativo complejo se ha convertido en un locativo no vinculado al desplazamiento, en un locativo no especificado. ${ }^{11}$ Este cambio de Locativo marcado (con desplazamiento) a Locativo no marcado implica una pérdida de especificaciones que tiene su correlato en el paso de TAL a TAA. ${ }^{12}$

En los ejemplos de (5b, c, d) hay un clítico dativo que se interpreta como el experimentador del proceso o estado físico y siempre se establece una relación de posesión inalienable entre este elemento y el locativo que designa la parte del cuerpo del individuo experimentador: $l i-$ nas en $(5 \mathrm{~b})$ y $(5 \mathrm{~d})$. Como es característico de muchos complementos dativos, el clítico dativo puede coaparecer fácilmente con

\footnotetext{
${ }^{8}$ Se agradece esta observación a un revisor anónimo.

${ }^{9}$ En rumano se usan dos verbos distintos para este tipo de frases: las equivalentes a (5b) se construyen con el verbo a ieşi 'salir' (sangre, mocos, pus, etc.), mientras que en las correspondientes a (5c) el verbo utilizado es a apărea 'aparecer' (mancha, peca, costra, etc.).

${ }^{10}$ Este locativo (al nas en (5d)) es no direccional a pesar de que vaya introducido por la preposición $a$ que en catalán puede indicar una meta (Va a Girona). Esta imposibilidad se refleja en la traducción castellana Le ha salido un grano en la nariz, donde la preposición empleada es en, la propia de los locativos no direccionales (Está en Barcelona), y no a, que suele indicar dirección (Meta). Nótese también que este complemento se puede sustituir por aquí, pero no por hacia aquí.

${ }^{11}$ También este complemento locativo se puede considerar un argumento, ya que el sentido del verbo en construcciones como las de $(5 \mathrm{c}, \mathrm{d})$, equivalente al de aparecer, implica necesariamente la existencia de un lugar donde tiene lugar la aparición.

${ }^{12}$ El ejemplo de (5b) corresponde a un "paso intermedio" en esta "degradación" del verbo sortir: desaparece la parte correspondiente a la Meta del complemento locativo complejo, pero se mantiene el Origen, y el Tema continúa siendo TAL (no TAA).
} 
un sintagma léxico que expresa la misma función (configuración típica de doblado de clítico y sintagma): A la Maria li ha sortit un gra al nas. Este complemento dativo (A la Maria) doblado por el clítico li podría ocupar la posición estructural de sujeto en la oración (un "sujeto caprichoso" o quirky subject), ya que, al tratarse de un verbo inacusativo, esta posición quedaría libre. De acuerdo con el análisis de los sujetos caprichosos (Fernández Soriano, 1999) el argumento Tema de (5b)(5c) ocuparía la posición del argumento interno y acabaría siendo el sintagma que concuerda con el verbo. Entonces, una diferencia sintáctica relevante entre el uso prototípico (5a) y los usos que expresan afección (5b-d) es que en el primero el Tema (TAL) se desplaza desde su posición de argumento interno a la posición estructural de sujeto (Especificador de Sintagma Tiempo) y que en los segundos esta posición es ocupada por el dativo (sujeto caprichoso) y el Tema (TAA) permanece en su posición original.

Por lo que se refiere al verbo venir, se puede observar un comportamiento parcialmente equivalente al de sortir. En (6) se presentan las estructuras más relevantes:

(6) a. En Joan ha vingut de l'escola (cap aquí) TAL Origen Meta 'Juan ha venido de la escuela (hacia aquí)' En Joan ha vingut (cap) aquí (des de l'escola) TAL Meta Origen 'Juan ha venido (hacia) aquí (desde la escuela)'

b. Li ha vingut son $\left(*\right.$ dels ulls $/{ }^{*}$ als ulls $) \quad$ TAA * Origen *Meta 'Le ha venido [entrado] sueño (*de los ojos/*en los ojos)'

c. Li ha vingut fred als peus TAA Loc 'Le ha venido [entrado] frío en los pies'

$\mathrm{Al}$ igual que sortir, venir se construye, en su uso prototípico, con locativos de Origen y Meta. Estos complementos son imposibles en la versión en que se expresa una afección, como refleja (6b), y en su lugar puede aparecer un locativo sin especificación direccional (6c). Este locativo establece una relación de posesión inalienable con un dativo ( $l i$ en $(6 c)$ ) que ocuparía la posición propia de los sujetos caprichosos. La diferencia respecto a sortir es que con venir no existe la posibilidad de preservar el complemento locativo de origen, como en (5b).

Por último, el verbo agafar, en su valor prototípico como el de (7a), es un verbo transitivo con un sujeto agente que controla la acción y un Tema afectado por cambio de locación, y permite la aparición de un complemento locativo de origen. En el ejemplo de (7b), con el objeto directo febre, se obtiene un sentido que ya no es una acción sino un proceso abstracto. En este caso, el sujeto se interpreta como Experimentador y el objeto es un Tema afectado que indica la aparición de un estado. En (7c) los argumentos reciben los mismos papeles temáticos que en (7b), pero las relaciones sintácticas varían: el Experimentador aparece como dativo, do- 
blado por el clítico $l i$, y el Tema concuerda con el verbo:

(7) a. L'Eva ha agafat el cistell de terra 'Eva ha cogido el cesto del suelo'

b. L'Eva ha agafat fred / febre $(*$ del cos $) \quad$ Experimentador TAA $*$ Origen 'Eva ha cogido frío / fiebre (*del cuerpo)'

c. A l'Eva li ha agafat fred / febre $\left({ }^{*}\right.$ del cos $)$ Experimentador TAA * Origen 'A Eva le ha cogido [entrado] frío / [venido] fiebre (*del cuerpo)'

d. A l'Eva li ha agafat fred als peus Experimentador TAA (Loc) 'A Eva le ha cogido [entrado] frío en los pies)'

Los ejemplos de (7c, d) también corresponden, igual que (5b, c, d) y (6b, c), a construcciones con el Experimentador como sujeto caprichoso (dativo) y con el Tema en la posición de argumento interno y pueden admitir un complemento locativo no direccional. ${ }^{13}$ De nuevo, pues, el complemento Origen del uso prototípico no es posible cuando se hace referencia a la adquisición de una afección, como en (7b, c, d); el Tema deja de indicar un cambio de lugar y puede aparecer un locativo no direccional compatible con la idea de aparecer.

Cuando se elimina el Agente de la estructura temática prototípica del verbo agafar aparece un Experimentador, que puede actuar como sujeto nominativo en una estructura transitiva como la de (7b). También puede darse una conversión del verbo transitivo en un verbo inacusativo; en este caso, el Experimentador aparece en forma de dativo ocupando la posición de sujeto, como en (7c, d) y como sucedía con sortir y venir. Esta doble opción de sujeto nominativo - dativo no se $\mathrm{da}$ con los verbos sortir y venir puesto que, a diferencia de agafar, ambos son ya inacusativos. Esto implica que no asignan caso a su objeto y, por consiguiente, que no tienen argumento externo porque no pueden asignar papel temático a su sujeto (Burzio, 1986).

Tras esta presentación de las estructuras de las frases formadas con los verbos venir, sortir y agafar en sus valores prototípicos y no prototípicos, se puede concluir que los valores no prototípicos están vinculados a una serie de cambios de tipo sintáctico y semántico que afectan la estructura argumental del verbo y la interpretación del argumento Tema. Se enumeran a continuación:

a) En primer lugar, se constata que los tres verbos, en su uso prototípico, expresan un desplazamiento que implica un Origen y una Meta. Dos de estos verbos

\footnotetext{
${ }^{13}$ Como se verá más adelante (cf. 3.2), la imposibilidad de tener un complemento locativo como *al cap 'en la cabeza' o *al cos 'en el cuerpo' en frases como L'Eva ha agafat febre 'Eva ha cogido fiebre' o A l'Eva li ha agafat febre 'A Eva le ha cogido [venido] fiebre', está relacionada con las diferencias entre el alcance corporal de la fiebre y el del frío.
} 
son inacusativos (sortir y venir) y uno es transitivo (agafar); solo este último tiene un argumento externo y puede, por tanto, asignar caso acusativo.

b) En segundo lugar, se ha visto que el uso no prototípico de los verbos implica la desaparición de algunos argumentos (Origen, Meta y Agente) y la aparición de otros (Locativo, Experimentador). El cambio de Agente a Experimentador solo se produce con el verbo transitivo (agafar). Por otra parte, el uso no prototípico también implica el cambio en la interpretación del Tema, que pasa de ser un Tema afectado por un cambio de lugar a ser un Tema afectado por cambio de estado (aparición).

c) En tercer lugar, hay que señalar que en estos predicados suele aparecer un argumento dativo que mantiene una relación de posesión inalienable con el locativo que denota la parte del cuerpo, si está presente. Se ha considerado que el dativo que aparece con los tres verbos es un sujeto caprichoso, un tipo de sujetos que aparecen en las construcciones inacusativas de los predicados de afección de los tres verbos; en el caso del verbo agafar el dativo solo aparece en una de las dos versiones, la no transitiva. ${ }^{14}$

\subsection{Relación entre las estructuras con agafar, venir y sortir y las que contienen tenir}

A continuación se presentará brevemente la distribución de usos de estos tres verbos (agafar (tr. o inac.), venir y sortir) respecto a tenir.

(8) a. La Clara va agafar un refredat 'Clara cogió un resfriado'

A l'Eva li va agafar un atac de tos

'A Eva le cogió [vino] un ataque de tos'

b. A ella li ha vingut son

'A ella le ha venido [entrado] sueño'

c. A ell li ha sortit un gra al peu

'A él le ha salido un grano en el pie'

(9) La Rita té un refredat / un atac de tos / gana / son / un gra al nas 'Rita tiene un resfriado / una ataque de tos / hambre / sueño / un grano en el pie'

Las frases como las de (8), que expresan la adquisición o la manifestación de

\footnotetext{
${ }^{14}$ En futuros trabajos se podrán estudiar las relaciones entre todos estos factores desde un punto de vista más teórico, cosa que queda fuera de los objetivos y posibilidades de este artículo.
} 
afecciones con agafar, venir y sortir, acentúan la lectura dinámica de la situación; en este sentido serían verbos incoativos que expresarían un cambio de estado, físico o psicológico (De Miguel, 1999: 3024). Estas frases, como veremos más adelante, expresan un movimiento y ponen énfasis en las etapas en las que aparece una afección. ${ }^{15}$ Las estructuras de (9), con el verbo tenir, en cambio, indican estados que no están formados por fases sucesivas sino por momentos que son homogéneos y no evolucionan ni progresan (no son dinámicos, no hay movimiento). El hecho de que las estructuras con tenir hagan referencia a estados, y que las que se construyen con agafar, venir y sortir sean estructuras dinámicas, es lo que condiciona el uso de un verbo o de otro.

A menudo, la manera que tenemos de pensar en los eventos es a través del movimiento, aunque se trate de uno metafórico. La localización y el movimiento pueden ser la fuente real a partir de la cual se pueden construir nociones más abstractas como las que estudiamos en este artículo, ${ }^{16}$ como ha señalado Coll-Florit (2009: 67-68) para frases como He entered a state of euphoria 'Entró en un estado de euforia' o He is coming out of coma 'Está saliendo del coma' de Lakoff y Johnson (1980).

Como ya se ha dicho, venir y sortir son prototípicamente verbos de movimiento que también se pueden utilizar en catalán para expresar el movimiento metafórico de una afección hacia una persona o desde su interior (un movimiento de adquisición o de aparición). ${ }^{17}$ La persona es, en última instancia, la meta o destinataria del movimiento de la afección, por tanto, la que experimenta la afección (el dativo Experimentador). Aunque el papel temático Origen / Meta se pierda (no se pueda realizar sintácticamente), el movimiento se puede interpretar metafóricamente. El verbo agafar no es considerado habitualmente como verbo de movimiento, pero sí lo es, como hemos visto en el apartado anterior, en el sentido más prototípico, puesto que supone el movimiento o cambio de lugar de una entidad.

Según lo que se ha defendido en algunos modelos localistas y desde la Lingüística Cognitiva, los cambios de estado se pueden entender como movimientos, físicos o abstractos (según la metáfora mencionada a menudo en la bibliografía de

\footnotetext{
${ }^{15}$ Hay que tener en cuenta que junto a las estructuras con verbos como agafar (tr. o inac.) y venir también hay verbos formados a partir de las correspondientes raíces nominales, como marejar-se 'agafar mareig' (marearse 'coger mareo'), refredar-se 'agafar un refredat' (resfriarse 'coger un resfriado') y muchos otros. Estos verbos también pueden expresar un cambio de estado y el inicio de uno nuevo, como en En Joan s'ha marejat 'Juan se ha mareado', igual que las estructuras que estudiamos en este trabajo.

${ }^{16}$ Algunos verbos de movimiento, como ir o venir del castellano, por ejemplo, se han gramaticalizado para indicar valores no relacionados con el movimiento físico, en estructuras como Va diciendo por ahi que es doctor (iy no lo es!') o Vengo diciendo desde hace tiempo que no durarán como pareja.

${ }^{17}$ Aunque este tipo de predicados expresan el movimiento ficticio de afecciones hacia la persona, no parece que se puedan incluir bajo la etiqueta de fictive motion que se ha utilizado en la Lingüística Cognitiva para caracterizar frases como This fence goes from the plateau to the valley 'Esta valla va desde la meseta hasta el valle' (Talmy, 2000).
} 
CHANGE IS MOTION), entre diferentes localizaciones o estados: el movimiento desde un estado 1 a un estado $2 .{ }^{18}$ Este continuum de movimientos implicados en el cambio tendría diferentes fases (adaptado de Coll-Florit (2009: 125)):

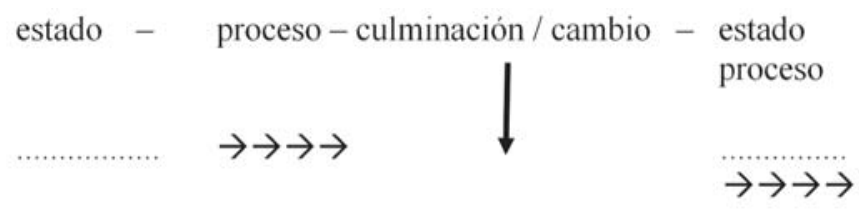

Figura 1

En el modelo propuesto por Moreno Cabrera (2003), las estructuras de las que nos ocupamos en este trabajo se considerarían procesos que implican una relación de transición entre estados (un cambio de estado). Más concretamente, serían mutaciones de adquisición porque implican un cambio de estado atributivo que supone que una entidad pasa de no tener una propiedad a tenerla (Moreno Cabrera, 2003: 129, 133). ${ }^{19}$

Las frases con agafar, venir y sortir, pues, focalizan el momento en que se produce el cambio de un estado a otro (la culminación de un proceso y la adquisición o manifestación de un nuevo estado). ${ }^{20} \mathrm{Si}$ las frases con agafar, venir y sortir representan, en esta línea evolutiva, el momento en el que se produce el cambio de estado, los predicados con tenir representan la fase posterior a ésta: expresan el periodo en el que una persona mantiene, durante un lapso de tiempo acotado (estados contingentes) o no acotados (estados absolutos), un estado que se ha iniciado en un momento anterior. En este sentido, podríamos decir que si una persona ha agafat o li ha vingut fred 'ha cogido o le ha venido [entrado] frío', esto implica que en una etapa posterior té fred 'tiene frío', de la misma manera que a una persona que li ha sortit un gra 'le ha salido un grano' en una etapa posterior té un gra 'tiene

\footnotetext{
${ }^{18}$ Cf. los trabajos clásicos de Jackendoff (1972), (1983) y (1990), de Anderson (1971) y (1977), o de Talmy (2000).

19 Según Moreno Cabrera (2003: 129), "las mutaciones se definen [...] como un cambio de estado pero no de estado locativo, sino atributivo. En un estado atributivo se predica una propiedad de una entidad. Pues bien, si se produce un cambio en esa propiedad, la entidad pasa a estar en un nuevo estado atributivo y se produce un proceso que denominamos mutación".

${ }^{20}$ En este sentido, pues, en el marco propuesto por Moreno Cabrera (2003) se podrían considerar logros complejos ingresivos, o mutaciones (simples o complejas). Para un estudio más detallado de la diferencia entre los logros simples y los complejos, cf. Pérez Saldanya (2002) y García Fernández (2006), entre otros.
} 
un grano'. ${ }^{21}$ Estas relaciones se ponen de manifiesto en ejemplos como los de (10):

(10) a. Fa deu dies que va agafar la grip i encara la té 'Hace diez días que cogió la gripe y todavía la tiene' Fa deu dies que li va sortir un gra i encara el té 'Hace diez días que le salió un grano y todavía lo tiene'

b. *Fa deu dies que va tenir la grip i encara l'agafa 'Hace diez días que tuvo la gripe y todavía la coge' *Fa deu dies que té un gra i encara li surt 'Hace diez días que tuvo un grano y todavía le sale'

El contraste entre los ejemplos de (10a) y los de (10b) muestra que hay un "orden" temporal entre las frases con tenir y las que se construyen con agafar, venir y sortir: estas últimas denotan un momento temporalmente anterior al estado expresado por las frases con tenir.

Tras esta caracterización de las estructuras con agafar, venir y sortir que son objeto de este estudio, en el apartado siguiente se estudiará cuáles son las propiedades de las afecciones que condicionan el uso de los distintos verbos, es decir, de qué manera la categorización que los hablantes hacen de ellas influye en la elección de una u otra estructura.

\section{FACTORES QUE INFLUYEN EN LA DISTRIBUCIÓN DE USOS DE LOS VERBOS Y DE LAS ESTRUCTURAS SINTÁCTICAS}

Los verbos agafar (tr. o inac.), venir y sortir se pueden utilizar para vehicular la relación entre una afección y una persona (o una parte de su cuerpo). Estos verbos, sin embargo, presentan algunas restricciones a la hora de combinarse con los nombres que expresan las afecciones. A continuación nos centraremos en tres de los factores que delimitan su uso y que están relacionados con algunas propiedades de las afecciones. En primer lugar, en los apartados 3.1 y 3.2 se analizarán dos rasgos de las afecciones que condicionan del mismo modo el uso de los tres verbos: su delimitación temporal (delimitación inicial y/o final) y su alcance corporal (total o parcial). Y en segundo lugar, en el apartado 3.3 se estudiará otra propiedad que diferencia los usos de los verbos: el origen de la afección (interno o externo al organismo). Hay que tener muy presente en todo momento que no siempre se trata de propiedades reales de las afecciones (como mínimo, desde el punto de vista de la medicina "oficial") sino de la manera en que son percibidas por los hablantes.

${ }^{21}$ Cf. Gràcia y Crous (2008) y Crous (2009) para el estudio de estructuras semejantes con el verbo fer 'hacer', como fer un infart 'hacer un infarto'. 
Verbos de movimiento, cambios de estado y categorización de afecciones / B. CROUS, LL. GRÀCIA

Se empezará por las propiedades que condicionan de la misma manera el uso de las cuatro estructuras estudiadas: las que incluyen el verbo agafar (tr. o inac.), venir o sortir.

\subsection{Delimitación temporal de la afección}

Partimos de la clasificación de las afecciones basada en el rasgo [ \pm delimitado] que presentamos en (11) y que ejemplificamos en (12), siguiendo lo propuesto en Gràcia y Crous (2008) y en Crous (2009):

$$
\begin{array}{ll}
\text { [+ delimitados por el inicio }] & =\text { adquiridos } \\
{[- \text { delimitados por el inicio }]} & =\text { congénitos } \\
{[+ \text { delimitados por el final }]} & =\text { curables } \\
{[- \text { delimitados por el final }]} & =\text { incurables }
\end{array}
$$

$$
\begin{array}{lll}
\text { INICIO } & \text { FINAL } & \text { EJEMPLOS } \\
+ & + & \text { gripe, varicela, gastritis, hepatitis A, sarampión } \\
+ & - & \text { sida, lepra, hepatitis } \mathrm{C} \text {, malaria, sífilis } \\
- & + & \text { algunas cardiopatías congénitas, estrabismo, infertilidad } \\
- & - & \text { síndrome de Down, gigantismo, nanismo, celiaquía }
\end{array}
$$

Las afecciones delimitadas por el inicio y por el final son enfermedades acotadas que afectan a la persona durante un periodo determinado de tiempo, como la gripe, y la mayoría de signos y síntomas (como la fiebre o la tos). Las que están delimitadas por el inicio pero no por el final son afecciones incurables que se pueden adquirir pero que, de momento, no se pueden dejar de tener (como el sida). Las afecciones que están delimitadas por el final pero no por el inicio son congénitas (no adquiridas fuera del útero materno) y actualmente son reversibles, como el estrabismo, por ejemplo, que a día de hoy se puede curar. Y, finalmente, si no están delimitadas ni por el inicio ni por el final, como el síndrome de Down, ni se adquieren ni, de momento, se pueden dejar de tener. Esta interpretación, basada en los rasgos [ \pm delimitado por el inicio] o [ \pm delimitado por el final], depende, muchas veces, de nuestra manera de concebir el mundo o de la situación actual de los avances médicos: una enfermedad como el sida actualmente no es curable, pero puede llegar el día en que lo sea y que, por lo tanto, cambie la interpretación.

Dicho esto, observamos que hay una restricción común al uso de los tres verbos de los que nos ocupamos (agafar (tr. o inac.), venir y sortir): las afecciones designadas por los nombres han de estar delimitadas por el inicio. Son verbos que indican un cambio de estado, y, por lo tanto, desde un punto de vista semántico, se puede decir que la afección pasa a estar en un sitio donde no estaba; es decir, se 
tiene que poder adquirir o tiene que poder aparecer, pero no puede ser congénita. Entonces el proceso denotado se puede interpretar a partir de una trayectoria (por lo menos en sentido figurado):
a. He agafat la grip / la sida 'He cogido la gripe / el sida'
b. M'ha agafat / vingut tos
vs. *la síndrome de Down 'el síndrome de Down'
'Me ha cogido [entrado]/venido tos' ' 'l sindrome de Down'
c. Em va sortir un gra
'Me salió un grano'
vs. *una taca de naixement ${ }^{22}$ una mancha de nacimiento'

Como se ve en estos ejemplos, solo los nombres que designan afecciones delimitadas por el inicio (independientemente de si lo están o no por el final) se pueden combinar con agafar (tr. o inac.), venir o sortir, porque, como ya hemos visto en el apartado anterior, son verbos que focalizan el momento en que esta afección empieza a manifestarse.

\subsection{Alcance corporal total o parcial}

Otro rasgo que comparten las estructuras con agafar (tr. o inac.), venir o sortir es, como ya se ha mencionado en 2.1, la posibilidad de poderse combinar con un complemento locativo que exprese la parte del cuerpo concreta donde se manifiesta la afección:
a. Va agafar una infecció (a l'orella)
'Cogió una infección (en la oreja)'
b. Li ha agafat dolor (a les cames)
'Le ha cogido [entrado] dolor (en las piernas)'
c. Li ha vingut dolor (a les cames)
'Le ha venido [entrado] dolor (en las piernas)'
Li ha sortit un gra (al braç)
'Le ha salido un grano (en el brazo)'

Si en algunos casos no es posible la aparición de este complemento locativo, esta imposibilidad no depende de los verbos, sino del alcance corporal de la afección:

\footnotetext{
${ }^{22}$ En el caso de sortir, cuando significa que una afección latente se manifiesta en la persona, se pueden encontrar frases como Tenia una cardiopatia de naixement, però no li ha sortit fins ara 'Tenía una cardiopatía de nacimiento, pero no le ha salido hasta ahora', en la que se expresa que una afección congénita se hace patente. Retomaremos este tema más adelante, en el apartado 3.3.
} 
A la Sara li va venir febre (*al cos) / migranya (*al cap)

'A Sara le vino fiebre (*en el cuerpo) / migraña (*en la cabeza)'

En efecto, según el alcance corporal que tienen, o que se percibe que tienen, las afecciones se pueden clasificar en tres grupos:

a. Afectan al cuerpo en general (o a ninguna parte en concreto): fiebre, sepsis, somnolencia, ictericia.

b. Solo pueden afectar a una determinada parte del cuerpo: migraña (la cabeza), taquicardia (el corazón), cat. ull de poll ('callo en los dedos del pie').

c. Pueden afectar a varias partes del cuerpo: dolor, picor, cáncer, infección.

En función del tipo de afección que denota el nombre que hace de sujeto concordado (con agafar (inac.), venir o sortir) o de objeto directo (con agafar (tr.)), puede haber o no un complemento que exprese la parte del cuerpo afectada que restringe la referencia del nombre que designa la afección. Así, a diferencia de lo que ocurre con los nombres de (16a, b), los que designan afecciones como las de (16c), que pueden afectar a varias partes del cuerpo, a menudo van acompañados de un sintagma preposicional (dolor a les cames 'dolor en las piernas', mal de coll 'dolor de garganta') ${ }^{23}$ o de un sintagma adjetival con un adjetivo relacional (dolor abdominal 'dolor abdominal'), que especifican el lugar concreto donde se localiza la afección. El hecho de que en ejemplos como los de (16b) la afección siempre se localice en una determinada parte del cuerpo hace que el complemento que la especifica no sea posible. ${ }^{24}$ Paralelamente, si la afección tiene alcance sobre todo el cuerpo en general, como en (16a), tampoco puede aparecer ningún complemento.

Hay que tener presente, sin embargo, que la clasificación concreta de una determinada afección en uno u otro grupo puede depender de la categorización semántica que se haga de las afecciones en cada lengua, que puede intervenir en la posibilidad que tiene el hablante de resaltar la parte del cuerpo concreta que interviene en la situación de afectación o no. Se puede imaginar una manera alternativa a la del catalán de expresar algunas afecciones. Imagínese, por ejemplo, una

\footnotetext{
${ }^{23}$ En el primer caso, con un sintagma preposicional con la preposición $a$, se podría considerar que dolor a les cames 'dolor en las piernas' es una oración reducida que funciona como complemento del verbo agafar en el ejemplo Ha agafat dolor a les cames 'Ha cogido dolor en las piernas', cuyo predicado sería el sintagma preposicional a les cames 'en las piernas' (Crous, 2009). En el segundo caso, en cambio, de coll 'de garganta' es un sintagma preposicional que modifica el núcleo nominal mal 'dolor' en un compuesto sintagmático.

${ }^{24} \mathrm{La}$ especificación de la parte del cuerpo afectada solo sería posible en casos como Li ha sortit un ull de poll al peu dret 'Le ha salido un callo en el pie derecho', porque el cuerpo humano tiene dos pies y se especifica en cuál de los dos se halla la afección.
} 
lengua en la que se clasificaran y designaran afecciones como la diarrea o el vómito a partir de una sola palabra de sentido general equivalente a evacuación. En esta lengua, a diferencia de lo que sucede en catalán, podría haber frases como las de (17a), con un sintagma preposicional que expresara la parte del cuerpo concreta afectada, comparable a otras del registro no técnico del catalán, como las de (17b):
a. Té evacuació de budells ('diarrea')
*Té diarrea de budells
'Tiene evacuación de tripas' ('diarrea')'
'(lit: tiene diarrea de tripas)'
Té evacuació d'estómac ('vòmit')
*Té vòmits d'estómac
'Tiene evacuación de estómago ('vómito')'
'(lit: tiene vómito de estómago)'
b. Té mareig de cap ('vertigen')
'lit: tiene mareo de cabeza ('vértigo')'
Té mareig de panxa ('nàusees')
'lit: tiene mareo de barriga' ('náuseas')'

En algunas lenguas el nombre equivalente a heces (o a la forma coloquial caca) se usa como núcleo de nombres compuestos que designan ciertas secreciones corporales; el otro elemento del compuesto se refiere a la parte del cuerpo donde aparece la secreción. En (18) se presenta un ejemplo del mandinka: ${ }^{25}$

$$
\begin{array}{lll}
\text { núm+búu } & \text { 'moco’ } & \text { nariz+caca } \\
\text { ñáa+búu } & \text { 'legaña' } & \text { ojo+caca } \\
\text { túlú+búu } & \text { 'cerumen' } & \text { oreja+caca }
\end{array}
$$

Así pues, la categorización de las afecciones (y, en este caso, el alcance corporal que se les asigna) interviene en el tipo y el número de complementos que pueden aparecer en las frases que se estudian y, por lo tanto, se puede afirmar que condiciona la estructura sintáctica de las frases con las que se expresa la manifestación de estas afecciones.

En las frases con nombres que designan afecciones que se pueden localizar en varias partes del cuerpo, como las de (16c), la expresión de la parte del cuerpo a través de un sintagma preposicional puede depender de la relevancia que asigne el hablante a la especificación de la parte del cuerpo directamente afectada. Es evidente que las partes del cuerpo constituyen la naturaleza de cualquier persona y, por lo tanto, "comparten" la afectación con la persona (el todo): si una afección o acción afecta a una persona también afecta a alguna de sus partes del cuerpo o al cuerpo en general, y viceversa. La expresión de la parte del cuerpo afectada, sin embargo, puede ser relevante y aparecer explícitamente en la frase expresando la

\footnotetext{
${ }^{25}$ El mandinka es una lengua de la familia nigerocongolesa hablada por alrededor de 1,5 millones de hablantes en Senegal, Gambia y Guinea-Bissau, principalmente.
} 
parte concernida, o bien no serlo y quedar implícita. Este hecho explicaría por qué en catalán puede haber frases como la de (19a) y otras como la de (19b):
a. A l'Eva li ha sortit un gra
'A Eva le ha salido un grano'
b. A l'Eva li ha sortit un gra al peu
'A Eva le ha salido un grano en el pie'

Si se analizan estos datos desde el punto de vista de la Lingüística Cognitiva, la naturaleza de estos complementos se puede relacionar con la noción de zona activa (active zone) de Langacker (1987). ${ }^{26}$ Las entidades que participan en una situación no suelen intervenir de manera indiferenciada, sino que lo más habitual es que participen a través de alguna de sus partes. En una frase como Tu perro mordió a mi gato, por ejemplo, se interpreta que solo unas zonas determinadas del perro (la mandíbula y los dientes) y del gato (la zona mordida, la cola) participan en la acción/efecto de morder, pero en esta frase no se especifican (adaptada de Langacker (2000: 62)); en Tu perro mordió a mi gato en la cola, en cambio, se observa que sí se especifica la zona activa del gato afectada por el mordisco. Las zonas o partes que participan directamente en la acción o en el estado designado por el verbo se denominan zonas activas, y pueden aparecer o no expresadas en la frase, según si se consideran zonas más o menos delimitadas y más o menos salientes o relevantes. Lo mismo ocurre en frases como las de (19), en las que el sintagma preposicional puede aparecer, como en (19b), o no aparecer, como en (19a). Como apunta Langacker $(1987,1991: 455)$, lo más habitual es que se tome el todo como lo más relevante (como en (19a)), y que no se especifique la zona activa.

Hasta aquí se ha visto dos de las propiedades de las afecciones que intervienen del mismo modo en el uso de las frases con agafar, venir y sortir: la delimitación temporal y el alcance corporal. En el apartado siguiente, se analizará una propiedad de las afecciones que puede explicar algunas de las diferencias en el uso de las distintas frases: el origen de la afección (interno o externo al organismo).

\subsection{Origen interno o externo al organismo}

Una de las propiedades de las afecciones que es relevante para explicar una parte de

\footnotetext{
${ }^{26}$ Según Sánchez López (2007: 162) los complementos locativos de frases como Yo lo golpeé (a Juan) en el brazo "do not modify the event but a part of the subevent structure that is involved in the affectation of one of their arguments". Para explicar la naturaleza de este tipo de complementos locativos, la autora recurre a la noción de default argument de Pustejovsky (1995: 63), que se refiere a los "parameters which participate in the logical expresion in the qualia, but which are not necessarily expresed syntactically".
} 
la distribución de los usos de los verbos agafar (tr. o inac.), venir y sortir es el hecho de que sea (o se interprete como) una afección causada por el propio organismo o bien por algún agente externo (un virus, una bacteria, etc.). Hay que tener en cuenta, sin embargo, que lo que presentaremos a continuación son tendencias de uso, porque las fronteras entre el uso de los distintos verbos estudiados en este trabajo no siempre son claras. A pesar de ello, es interesante observar cuáles son los factores que determinan una parte de los usos.

\subsubsection{Origen interno}

Cuando se interpreta que el origen de la afección es interno, es decir, que ha sido originada por el propio organismo, las formas más frecuentes son con agafar (inac.) y venir, que a menudo se usan en los mismos contextos, y sortir, que se combina con un número más limitado de palabras. Las estructuras con agafar (tr.) tienen un uso mucho más restringido. Esta selección de los verbos está en distribución parcialmente complementaria con la que se da cuando el origen de la afección se considera externo al organismo de quien la experimenta.

Los nombres que se refieren a afecciones producidas por el organismo de una persona, como decíamos, se combinan preferentemente con agafar (inac.) o venir:

(20) A la Marta li ha agafat / vingut migranya / vertigen / son / gana / febre / picor / tremolor de cames / mareig / (el) singlot / badallera $^{27}$

'A Marta le ha cogido [entrado] / venido migraña / vértigo / sueño / hambre / fiebre / picor / temblor de piernas / mareo / hipo / ganas de bostezar'

Pero a pesar de que agafar (inac.) y venir muestran unos usos muy parecidos cuando se expresa la manifestación de afecciones, no siempre son intercambiables:

(21) a. Li ha vingut la regla / un rot / un esternut / un badall 'Le ha venido la regla / un eructo / un estornudo / un bostezo'

b. Li ha agafat *la regla / ??un rot / ?un esternut / ?un badall

'*Le ha cogido [entrado] la regla / un eructo / un estornudo / un bostezo'

Hay que señalar que, en estos contextos, los verbos agafar (inac.) y venir casi siempre se combinan con nombres que expresan signos, síntomas o afecciones

\footnotetext{
${ }^{27}$ Los nombres deverbales del catalán formados con el sufijo - era que indican 'ganas de + V', como badallera 'ganas de bostezar', se combinan con agafar (inac.) y venir, y no con agafar (tr.). Esto confirmaría que las estructuras con estos dos verbos suelen expresar la manifestación de afecciones físicas o psicológicas que tienen un origen interno, como en este caso las ganas o la necesidad de hacer una determinada acción fisiológica. Para más información sobre este tipo de nombres deverbales con el sufijo - era, cf. Gràcia y Riera (2003).
} 
no necesariamente patológicos, como son 'sueño', gana 'hambre', febre 'fiebre', picor 'picor', pipi 'pipí', etc. Son más extrañas las frases con nombres que se refieren a enfermedades propiamente dichas, como artrosi 'artrosis', Parkinson 'Parkinson' o demència 'demencia'. Además, las afecciones cuyos nombres se combinan más fácilmente con estos dos verbos suelen estar delimitadas no solo por el inicio sino también por el final, es decir, afecciones que se adquieren y que son curables.

En cuanto a sortir, cuando se utiliza combinado con un nombre referido a una afección (un grano, una verruga, etc.), normalmente significa que ésta aparece en una superficie externa (un gra al braç 'un grano en el brazo') o interna (una llaga a l'estómac 'una úlcera en el estómago'), pero sin implicar que ya existía internamente y que se ha desplazado hacia fuera (como se ha visto en 2.1, se ha perdido el valor de trayecto propio del verbo en su uso prototípico). Esto es muy claro cuando se expresan lesiones o anomalías físicas, especialmente de la piel. Además, estas afecciones generalmente están provocadas por el propio organismo de la persona, como se ve en (22a), o son reacciones del cuerpo, no inmediatas, a una causa externa, como en (22b). Esto explica que frases como las de (23) no sean posibles, puesto que se trata de afecciones causadas directamente por un factor externo:

(22) SORTIR

a. Li ha sortit una berruga al coll / una piga / un ull de poll al peu dret 'Le ha salido una verruga en el cuello / un lunar / un callo en el pie derecho'

b. Li ha sortit una llaga al peu / un blau a la cama

'Le ha salido una úlcera en el pie / un morado en la pierna'

${ }^{*}$ Li ha sortit una picada / una cremada al braç

'*Le ha salido una picadura / una quemadura en el brazo'

Las lesiones o anomalías de (23) no tienen su origen en el organismo de la persona afectada, sino que son afecciones que no pueden aparecer si previamente no ha intervenido algún factor externo. Esto provoca que sean frases inaceptables en catalán con el verbo sortir.

Aparte de ser provocadas por el propio organismo de la persona, las afecciones cuyos nombres se combinan con sortir suelen referirse a entidades que tienen una existencia física y visual situadas en una superficie interna (Ilaga a l'estómac 'úlcera en el estómago') o externa (llaga al peu 'úlcera en el pie'). Obsérvese que los nombres que designan a este tipo de afecciones, en cambio, no se pueden combinar con verbos como agafar (tr. o inac.) o venir:

(24) A l'Eva li van sortir dues butllofes als peus i una berruga al nas 
'A Eva le salieron dos ampollas en los pies y una verruga en la nariz'

*L'Eva va agafar dues butllofes als peus i una berruga al nas

'*Eva cogió dos ampollas en los pies y una verruga en la nariz'

*A l'Eva li van agafar/venir una berruga al nas i dues butllofes als peus

'*A Eva le cogieron/vinieron dos ampollas en los pies y una verruga en la nariz'

También hay ejemplos en los que las frases con sortir expresan la manifestación de afecciones físicas, como la fiebre, el asma o un resfriado, o psicológicas, como la angustia. En este caso, las frases significan que esta afección, que estaba latente u oculta, se manifesta abiertamente en la persona:

(25) M'està sortint / ja m'ha sortit el refredat

'Me está saliendo / ya me ha salido el resfriado'

Li està sortint / li ha sortit tota l'angoixa acumulada durant l'últim any

'Le está saliendo / le ha salido toda la angustia acumulada durante el último año'

Tenia una cardiopatia congènita però no li ha sortit fins ara

'Tenía una cardiopatía congénita pero no le ha salido hasta ahora'

En las frases de (25), independientemente del origen interno o externo de la afección, e incluso de si ésta es adquirida o congénita, se mantiene el sentido básico del verbo: indicar un movimiento de dentro hacia afuera, de un estadio en el que la patología está latente, a otro en el que es patente. ${ }^{28}$

\subsubsection{Origen externo}

Los nombres que designan afecciones cuyo origen es percibido como externo, es decir no provocadas por el organismo del propio individuo sino por un virus, una bacteria, un microbio, hongos o cualquier otro organismo externo, aparecen preferentemente en las estructuras transitivas con el verbo agafar, como en (26a). Como se ve en (26b), actualmente estos nombres difícilmente se combinan con venir ${ }^{29}$ o agafar (inac.), aunque en este último caso no son del todo imposibles. En este grupo de afecciones estarían los nombres que designan enfermedades infecciosas como los de (26):

\footnotetext{
${ }^{28}$ En el caso del uso de la perífrasis progresiva con el verbo sortir 'salir' (m'està sortint...), se produciría una coerción que modificaría el valor aspectual del verbo, de manera que, a pesar de ser un logro, en este contexto admite la forma progresiva (Escandell y Leonetti, 2002). Agradecemos el comentario a un revisor anónimo.

${ }^{29}$ Por lo que se refiere a ràbia 'rabia', cuando este nombre se combina con venir actualmente no suele denotar la enfermedad infecciosa que lleva este nombre sino un estado de enojo violento; en estos casos se usa sin el artículo definido y, en cambio, acepta un cuantificador: Quan ho he vist, m'ha vingut molta ràbia!' 'cuando lo he visto, me ha venido mucha rabia'.
} 
a. AGAFAR (TR.)

Ha agafat la sida / la grip / el còlera / la pesta / la varicel.la / el xarampió / (la) malària / (la) sarna / el tètanus / la lepra

'Ha cogido el sida / la gripe / el cólera / la peste / la varicela / el sarampión / (la) malaria / (la) sarna / el tétanos / la lepra'

b. AGAFAR (INAC.)

Li ha agafat / vingut la sida / la grip / el còlera / la pesta / la varicel.la / el xarampió / (la) malària / (la) sarna / el tètanus / la lepra

'*Le ha cogido / venido el sida / la gripe / el cólera / la peste / la varicela / el sarampión / (la) malaria / (la) sarna / el tétanos / la lepra'

Con nombres como fongs 'hongos' e infecció 'infección', las frases más habituales también son con agafar (tr.), lo cual es coherente con la hipótesis de que este verbo expresa, sobre todo, afecciones que tienen un origen externo. Las frases de (27a) y (28a) son estructuras transitivas con el verbo agafar, como la presentada en (7b). En estas construcciones el sujeto es nominativo y el objeto, acusativo (ella ha agafat el tifus), pero, a diferencia de lo que sucede cuando se usa el verbo en su valor prototípico, el sujeto se interpreta como experimentador y no como agente:

(27) a. A la piscina he agafat fongs als peus 'En la piscina he cogido hongos en los pies'

b. *A la piscina m'han agafat / vingut fongs als peus

'*En la piscina me han cogido / venido hongos en los pies'

(28) a. En Samuel ha agafat una infecció a l'ull dret 'Samuel ha cogido una infección en el ojo derecho'

b. A en Samuel li ha agafat / vingut una infecció a l'ull dret

'*A Samuel le ha cogido / venido una infección en el ojo derecho'

Como ya se ha visto en el apartado 2.1 , los diccionarios recogen este matiz distintivo a la hora de expresar la manifestación de afecciones: mientras que la definición correspondiente a la forma transitiva de agafar es "Contreure (ex. agafar un cadarn)» 'Contraer (ej. coger un resfriado)', la definición para venir es "Produir-se en un ésser viu un fenomen fisiologic o anímic (ex. venir son, el singlot)" 'Producirse en un ser vivo un fenómeno fisiológico o anímico (ej. venir sueño, hipo)', y para agafar (inac.) es "Sobrevenir (ex. agafar fred)" 'Sobrevenir (ej. coger frío)'. Estas definiciones ponen de manifiesto la intuición de los hablantes de que mientras que las frases con agafar (tr.) pueden expresar la manifestación de afecciones adquiridas que vienen de fuera, las frases con agafar (inac.) y venir suelen denotar procesos internos del organismo. A pesar de ello, se puede encontrar algunos nombres que 
hacen referencia a signos o síntomas producidos por el organismo de la persona, o que se supone que lo son, que no solo aceptan agafar (inac.) y venir, sino también agafar (tr.), como los de (29): ${ }^{30}$

(29) He agafat / Al noi li ha agafat/vingut son / gana / set / fred / mareig / vertigen / dolor 'He cogido / Al chico le ha cogido/venido [entrado] sueño / hambre / sed / frío / mareo / vértigo / dolor'

Existe otro verbo transitivo que aún no hemos mencionado y que también se puede utilizar en catalán para expresar que una afección se empieza a manifestar en una persona: arreplegar 'agarrar, pillar (lit. recoger)'. Como se ve en (30a), junto con la acepción prototípica de este verbo, que es muy parecida a la de agafar, el DIEC2 también recoge su uso para expresar la manifestación de afecciones: "Ésser atacat (per una malaltia). El meu cosí ha arreplegat una pulmonia" 'Ser atacado (por una enfermedad). Mi primo ha pillado una pulmonia':
a. Va arreplegar un refredat / la grip / una pulmonia / la sida / la lepra / el tifus
'Pilló un resfriado / la gripe / una pulmonía / el sida / la lepra / el tifus'
b. $\quad{ }^{*} \mathrm{Ha}$ arreplegat son / fred / calfreds / tremolors / nàusees / vertigen ‘*Ha pillado sueño / frío / escalofríos / temblores / náuseas / vértigo'

Si venir es el verbo de uso más generalizado actualmente para expresar la manifestación de afecciones producidas por el organismo de la persona, arreplegar es el que, en el registro coloquial, se usa de manera más clara cuando se trata de afecciones que tienen o se entiende que tienen un origen externo, como muestra el contraste entre (30a) y (30b). ${ }^{31}$

\footnotetext{
${ }^{30}$ Entre los usos de agafar (tr.) y de agafar (inac.), parece haber una diferencia relacionada con el hecho de que haya o no una causa externa que provoque la afección. Una frase como Nen, abriga't, que està nevant $i$ agafaràs fred, amb màniga curta 'Niño, abrígate, que está nevando y cogerás frío, con manga corta' es preferible a otra con el uso inacusativo de agafar: Nen, abriga't, que està nevant i t’agafarà fred, amb màniga curta 'Niño, abrígate, que está nevando y te cogerá [entrará] frío, con manga corta'. Sería interesante estudiar más exhaustivamente en otro trabajo el grupo de ejemplos presentados en (29), mayoritariamente con nombres que hacen referencia a síntomas, y ponerlos en relación con las estructuras de los verbos psicológicos del tipo molestar, con las que guardan ciertas semejanzas, aunque no son coincidentes. Este objetivo cae fuera de las posibilidades de este artículo.

${ }^{31} \mathrm{~F}$. Roca nos ha hecho notar que en el contraste entre (30a) y (30b) podría influir el hecho de que en el primer caso el objeto contiene un determinante y en el segundo, no. El tema de la definitud de los SN que designan afecciones que se han tratado en este artículo merecería un estudio mucho más profundo que el que se le podría dedicar aquí.
} 


\section{CONCLUSIONES}

En este trabajo se ha estudiado la relación entre la categorización que los hablantes hacen de las afecciones y el uso de los verbos catalanes agafar 'coger, agarrar', venir 'venir' y sortir 'salir' cuando expresan la aparición de éstas. Autores como Moreno Cabrera (2003) ya han apuntado que detrás de este uso está el recurso a una metáfora del movimiento según la cual hay una entidad que se mueve hacia un lugar. En las estructuras estudiadas, la mayoría de las veces es la afección la que "se mueve" hacia la persona o desde el interior de la persona. Así, el cambio de estado que supone la manifestación de una afección se equipara al movimiento. La expresión de la aparición de afecciones es, en este sentido, un dominio secundario en comparación con el uso prototípico de estos verbos de movimiento y adquisición. En estas construcciones, con agafar (inac.), venir y sortir aparece un complemento dativo que representa a la persona afectada (el Experimentador) y que suele aparecer al inicio de la frase, como sujeto caprichoso. De los verbos estudiados, agafar (tr. o inac.) y venir expresan un movimiento centrípeto, es decir, que tiende hacia la persona como centro; sortir, en cambio, expresa un movimiento centrífugo, de manifestación de una afección desde la persona. Se ha visto, por otra parte, que para expresar que una persona padece una afección, en catalán también se usa el verbo tenir. El uso de estos dos tipos de frases está en distribución complementaria: mientras que las estructuras con agafar (tr. o inac.), venir y sortir expresan un cambio de estado, la culminación de un proceso y la adquisición o manifestación de un nuevo estado, las frases con tenir expresan el mantenimiento de un estado durante un espacio más o menos acotado de tiempo.

Se partía de la hipótesis de que la categorización de las afecciones era un factor que podía condicionar el uso de determinadas estructuras sintácticas, en el caso que nos ocupa, con los verbos agafar (tr. o inac.), venir y sortir. Se ha constatado la existencia de dos factores que condicionan del mismo modo los predicados estudiados: por un lado, las afecciones cuyos nombres se combinan con estos verbos de movimiento han de tener el rasgo [+delimitado por el inicio], es decir, han de ser consideradas afecciones que se puedan adquirir, como es esperable por la propia naturaleza de los verbos, que expresan la adquisición o manifestación de un nuevo estado. Por otro lado, se ha visto que la manera de categorizar las afecciones interviene en el alcance corporal que se les asigna: en algunos casos se interpreta que la afección afecta a todo el cuerpo en general o a ninguna parte en concreto (la fiebre); en otros casos, en cambio, se interpreta que puede afectar a una única parte del cuerpo (la migraña), y, finalmente, en otros se entiende que la afección puede afectar a distintas partes (infección). En el caso de las afecciones que pueden afectar a más de una parte del cuerpo, el hablante puede explicitar la parte del cuerpo directamente afectada por la afección (la zona activa) a través de un complemento. 
Finalmente, se ha detectado otro factor que sí influye en la selección de uno u otro verbo. En el caso de agafar (tr. o inac.) y venir se cree que se puede trazar una línea en función de la tendencia más o menos marcada de los verbos a combinarse con nombres que se refieren a afecciones a las que se atribuye un origen externo o un origen interno. En un extremo de la línea estarían las frases con venir, utilizadas mayoritariamente para expresar la manifestación de afecciones producidas por el organismo; en el otro extremo estarían aquellas en las que aparece el verbo arreplegar 'agarrar, pillar (lit. recoger)' (otro verbo similar a agafar que se puede usar en este tipo de construcciones), usadas para indicar la aparición de afecciones patológicas que tienen un origen externo. Entre estos dos extremos, los verbos agafar (tr. e inac.) tendrían un uso menos delimitado y se podrían utilizar para expresar la manifestación de ambos tipos de afecciones, aunque agafar (tr.) tendría usos más cercanos a arreplegar, es decir, con el valor de contreure 'contraer'; y en cambio agafar (inac.) tendría usos más cercanos a venir:

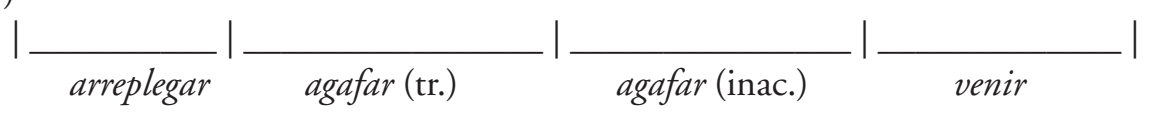

Nótese que entre los verbos de (31) hay una gradación: en su uso habitual los dos primeros son verbos agentivos con un objeto, pero también pueden aparecer en construcciones como las estudiadas aquí, con un sujeto nominativo experimentador y un objeto acusativo; son las estructuras que hemos llamado "intermedias". El primero, a diferencia del segundo, no admite una construcción inacusativa. Los dos últimos verbos, en cambio, funcionan como verbos inacusativos y tienen un dativo experimentador que aparece como sujeto caprichoso en la posición estructural de sujeto; el primero, agafar (inac.) tiene un correlato transitivo, pero venir es inacusativo en todos sus usos.

En cuanto al verbo sortir, también se suele combinar con nombres que designan afecciones provocadas por el propio organismo de la persona que suelen tener una existencia física y visual en una superficie del cuerpo (interna o externa) o, en un uso más marginal, con patologías que estaban latentes y se hacen patentes. En su uso más prototípico, expresa la aparición o manifestación de afecciones y, en este sentido, difiere de la distribución de los usos de los otros verbos (agafar (tr. o inac.) y venir), que no se pueden combinar con los nombres referidos a este tipo de afecciones.

Así pues, se ha aportado datos a favor de la hipótesis de la que se partió, porque en algunos casos el uso de los verbos estudiados está relacionado con la categorización de las afecciones. Todavía las autoras no tienen una explicación suficientemente adecuada para algunos aspectos relativos a la distribución de los usos de los 
Verbos de movimiento, cambios de estado y categorización de afecciones / B. CROUS, LL. GRÀCIA

verbos y a los factores de la categorización que intervienen en su selección y, por lo tanto, habrán de ser abordados en estudios posteriores.

\section{REFERENCIAS BIBLIOGRÁFICAS}

Anderson, John M. (1971). The Grammar of Case: Towards a Localistic Theory. Cambridge: Cambridge University Press.

Anderson, John M. (1977). On Case Grammar. Londres: Croom Helm.

Belletti, Adriana (1988): The case of inaccusatives. Linguistic Inquiry, 19, 1-34.

Burzio, Luigi. (1986). Italian Syntax. A Government-Binding Approach. Dordrecht: Reidel.

Coll-Florit, Marta. (2009). La modalitat de l'acció. Anàlisi empírica, reformulació teòrica i representació computacional. Tesis doctoral. España: Universitat Oberta de Catalunya.

Crous, Berta. (2009). Estudi interlingüístic de les construccions que expresen estats patològics en catalán i en mandinga. Tesis doctoral. Girona, España: Universitat de Girona. Disponible en: http://www.tdx.cat/bitstream/handle/10803/7829/tbcc.pdf;jsessionid=D864D357FA9E450E485417B3508459 BB.tdx2? sequence $=1$

CTILC = Corpus Textual Informatitzat de la Llengua Catalana. Institut d'Estudis Catalans. Disponible en http://ctilc.iec.cat/

De Miguel, Elena. (1999). "El aspecto léxico". En Bosque, Ignacio y Demonte, Violeta (dirs.). Gramática Descriptiva de la Lengua Española. Madrid: Espasa Calpe, 2977-3060 (vol. 2).

DIEC2 = Institut d'Estudis Catalans. Diccionari de la llengua catalana (2 $2^{\mathrm{da}}$ edic.). Disponible en: http://dlc.iec.cat/

Escandell, Victoria y Leonetti, Manuel (2002): "Coercion and the stage / Individual Distinction”. En Gutiérrez-Rexach, Javier (ed.). From Words to discourse. Trends in Spanish Semantics and Pragmatics. Oxford: Elsevier, 159-179.

Fernández-Soriano, Olga. (1999): Two Types of Impersonal sentences in Spanish: Locative and Dative Subjects. Syntax 2, 101-140.

García Fernández, Luis. (dir.) (2006). Diccionario de perifrasis verbales. Madrid: Editorial Gredos.

Gràcia, Lluïsa. (1989a). La teoria temàtica. Barcelona: Servei de Publicacions de la Universitat de Barcelona.

Gràcia, Lluïsa. (1989b). Els verbs ergatius en català. Ciutadella: Institut Menorquí de Estudis y Ajuntament de Ciutadella.

Gràcia, Lluïsa y Crous, Berta. (2008). "Sobre algunos predicados con fer y tenir en catalán: fer un infart vs. tenir un infart”. En Artiagoitia, Xabier y Lakarra, 
Joseba Andoni (eds.). Gramatika Jaietan Patxi Goenagaren omenez [La gramática está de fiesta. En homenaje a Patxi Goenaga], Anejos de ASJU. Bilbao y Donostia: Universidad del País Vasco y Diputación Foral de Gipuzkoa, 351-362.

Gràcia, Lluïsa y Riera, Laura. (2003). A propos des noms déverbaux avec le suffixe - era du catalan. Cahiers de Grammaire, 28, 153-161.

Jackendoff, Ray S. (1972). Semantic Interpretation in Generative Grammar. Cambridge, Mass.: The MIT Press.

Jackendoff, Ray S. (1983). Semantics and Cognition. Cambridge, Mass.: The MIT Press.

Jackendoff, Ray S. (1990). Semantic Structures. Cambridge, Mass.: The MIT Press.

Lakoff, George. (1987). Women, Fire, and Dangerous Things: What Categories Reveal about the Mind. Chicago, Londres: University of Chicago Press.

Lakoff, George y Johnson, Mark. (1980). Metaphors We Live By. Chicago, Londres: University of Chicago Press.

Langacker, Ronald W. (1987, 1991). Foundations of Cognitive Grammar. Stanford (California): Stanford University Press (vol. I: Theoretical Prerequisites. Vol. II: Descriptive Application).

Langacker, Ronald W. (2000). Grammar and Conceptualization. Berlín, Nueva York: Mouton de Gruyter.

Levin, Beth. (1993). English Verb Classes and Alternations: A Preliminary Investigation. Chicago, Londres: The University of Chicago Press.

Levin, Beth y Rappaport, Malka. (1995). Unaccusativity: at the syntax-lexical semantics interface. Cambridge, Mass.: The MIT Press.

Moreno Cabrera, Juan Carlos. (2003). Semántica y gramática. Sucesos, papeles semánticos y relaciones sintácticas. Madrid: Machado Libros S.A. Lingüística y conocimiento, 35.

Pérez Saldanya, Manuel. (2002). "Les relacions temporals i aspectuals". En Solà, Joan. [et al.] (dirs.). Gramàtica del Catalán Contemporani. Barcelona: Editorial Empúries, 2567-2662 (vol. 3).

Pustejovsky, James. (1995). The Generative Lexicon. Cambridge, Mass.: The MIT Press.

Sánchez López, Cristina. (2007). The possessive dative and the syntax of affected arguments. Cuadernos de Lingüistica del I. U. I. Ortega y Gasset, 14, 153-173.

Talmy, Leonard. (2000). Towards a Cognitive Semantics I y II: Concept Structuring Systems. Cambridge, Mass.: The MIT Press. 